\title{
Adjunctive Orthodontic Treatment with Lingual Orthodontic System
}

\author{
Kafle D, Humagain M, Upadhaya C
}

Department of Dentistry

Kathmandu University School of Medical Sciences

Dhulikhel Hospital, Kathmandu University Hospital

Dhulikhel, Nepal

Corresponding Author

Dasharath Kafle

Department of Dentistry

Kathmandu University School of Medical Sciences

Dhulikhel Hospital, Kathmandu University Hospital

Dhulikhel, Nepal

E-mail: dashrath07@yahoo.com

Citation

Kafle D, Humagain M, Upadhaya C. Adjunctive Orthodontic Treatment with Lingual Orthodontic System. Kathmandu Univ Med J 2011;36(4):306-9.

\begin{abstract}
The lingual orthodontic therapy though started in 1972, could not be popular till the beginning of 1990. In Nepal it does not have a history of more than a year. It is started in Dhulikhel Hospital for the first time in Nepal. Usually orthodontic therapy is meant for putting braces on the labial surface of the teeth which is called labial orthodontic system. Lingual orthodontic system is a purely invisible kind of orthodontic therapy in which braces are placed behind the teeth. The advantages of lingual orthodontic therapy are: invisibility, better biomechanics and improved patient compliance. On the other hand it is difficult to master and costlier than labial orthodontics. We have presented six adjunctive orthodontic cases treated by lingual system with the same end result comparable to labial orthodontic system.
\end{abstract}

\section{KEY WORDS}

invisible, labial , lingual, orthodontics

\section{INTRODUCTION}

According to William Proffit the adjunctive orthodontic treatment is defined as the tooth movement carried out to facilitate other dental procedures necessary to control disease, re store function and / or enhance appearance. ${ }^{1}$ Adjunctive orthodontic treatment usually does not last more than six months. Closure of the midline diastema, elimination of anterior black triangle, uprighting of the tilted teeth, relieving cross bite and anterior space redistribution usually fall under this category.

However the upper anterior midline diastema and black triangles are the common problem encountered in daily clinical practice. The incidence of maxillary midline diastema is reported in the range of $5 \%$ to $20 \% .^{2-5}$ The aetiology of the midline daistema may be high and thick frenal attachment, tooth size discrepancy, alveolar clefts, oral habits, pathosis in the midline area, deep overbite, genetic predisposition, periodontal tooth migration and posterior bite collapse. , $^{3,-9}$ There are different treatments options available for the correction of the midline diastema among which restorative, prosthetic, orthodontic and/or surgical treatment are the routine procedure. ${ }^{7,10-17}$ While treating the midline diastema, it is always important to assess the aetiology of the problem. If the diastema is due to size and shape abnormality of the teeth, composite build up or veneering is the good option after space redistribution. But if the teeth are of normal size, orthodontic treatment is the best possible solution. However due to the visible nature of the orthodontic appliances, most of our patients land up with over size veneering or aesthetically unpleasant composite build ups. The hindrance to orthodontic treatment in adult and young adults are the visibility of the appliances. If we give the option of the invisible kind of appliances, most patients readily accept the treatment plan. Clear Aligner therapy and lingual orthodontic treatment are the invisible way of treating the malocclusion so far available. However aligner is not purely invisible as it is a transparent sheet closely adapting to the teeth. Lingual orthodontic appliances as being placed on the palatal/lingual surface of the teeth can be considered invisible though it is uncomfortable for the time being. ${ }^{18,19}$ In this article we will present series of cases with upper midline diastema and black triangles treated with simple orthodontic appliances at Dhulikhel Hospital, Kathamandu University Hospital. 


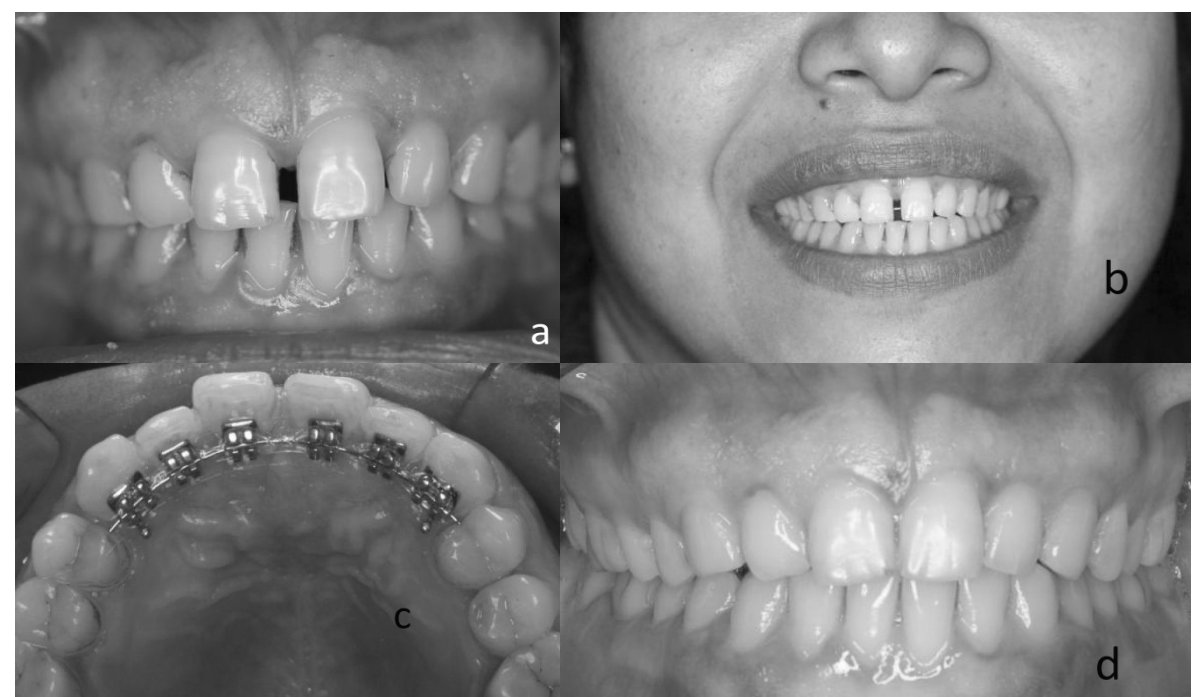

Figure 1. Case one a. Initial, b. After bonding lingual appliance, c. Lingual appliance in situ, d. At the end of the treatment

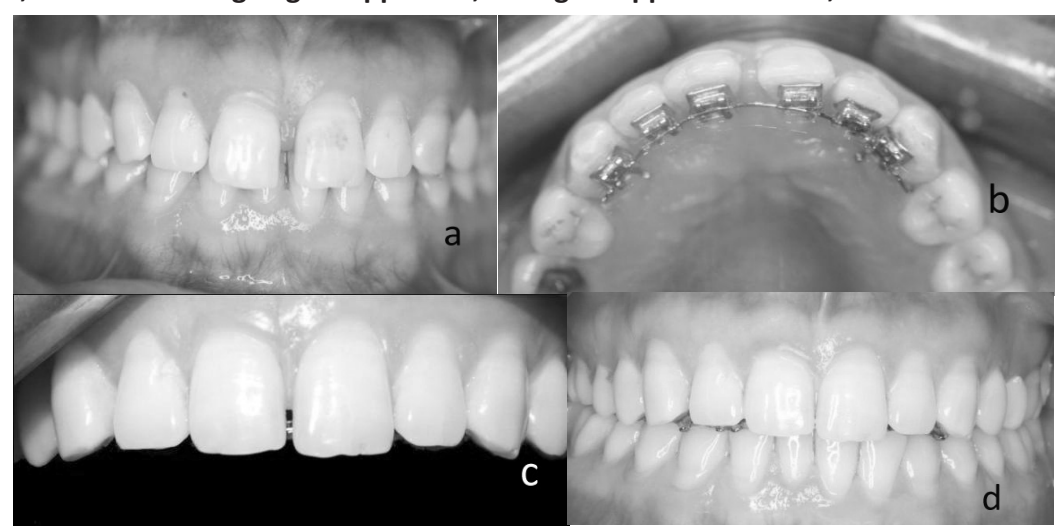

Figure 2. Case two a.Initial, b.Occlusal, c. Improvement, d.After treatment

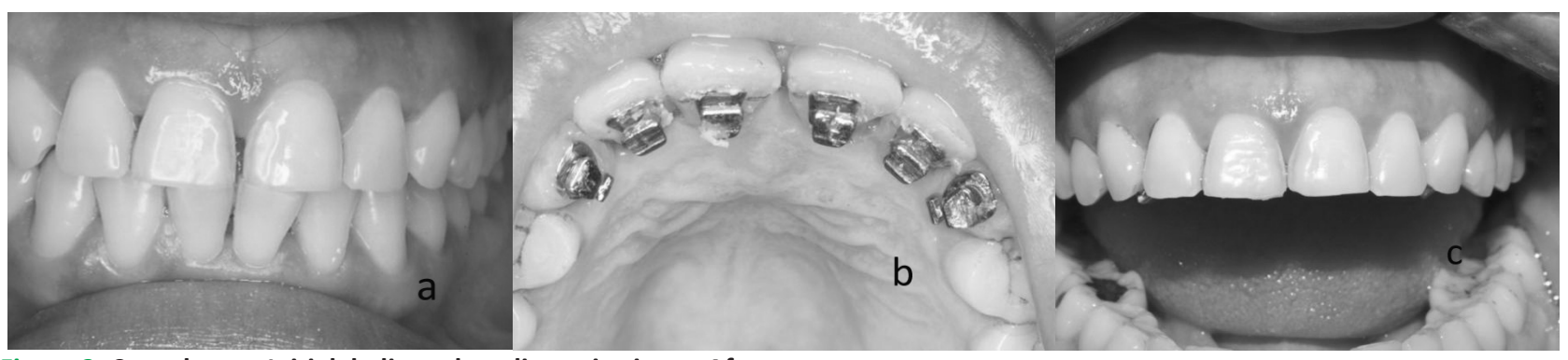

Figure 3. Case three a.Initial, b. lingual appliance in situ, c. After treatment

\section{CASE REPORT}

\section{Case one}

Thirty five years old female patient came to the Kathmandu University School of Medical Sciences, Dhulikhel Hospital, dental clinic with the chief complain of spacing between anterior teeth and unaesthetic appearance while smiling. On examination, four millimeters midline disatema was noted. Different available treatment options were discussed with the patient and she accepted the lingual method. The space was closed with 0.018 " stainless steel wire with e-chain application. Treatment time was four months. Patient was given fixed retainer.

\section{Case two}

Thirty six years old female patient with similar problem presented to University Hospital with midline gap between upper front teeth. On examination of oral cavity, upper left second premolar was found to be root treated. After discussing different treatment options, patient agreed for lingual therapy. By the same mechanics as in case one, space closure was carried out. However this case took more time to finish because of the gingival encroachment in between upper two centrals. At the end of the treatment mild step deformity was seen between two central incisors for which few wire bendings were carried out. The case was finished at 6 months and patient is now on fixed retention.

Case three

Thirty three years old female patient presented to us with the chief complain of gap between anterior teeth. She complained of progressive increase in gap during the 


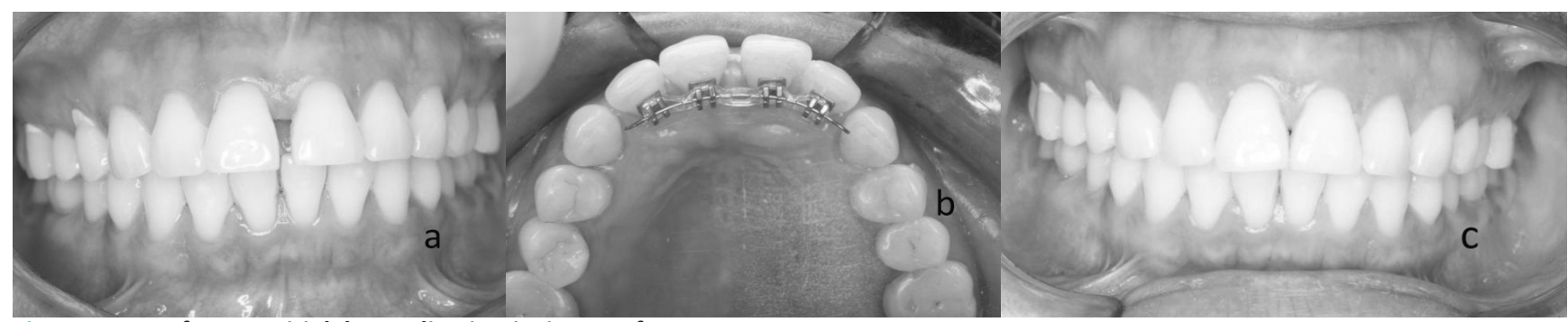

Figure 4. Case four a. Initial, b. Application insitu, c. After treatment

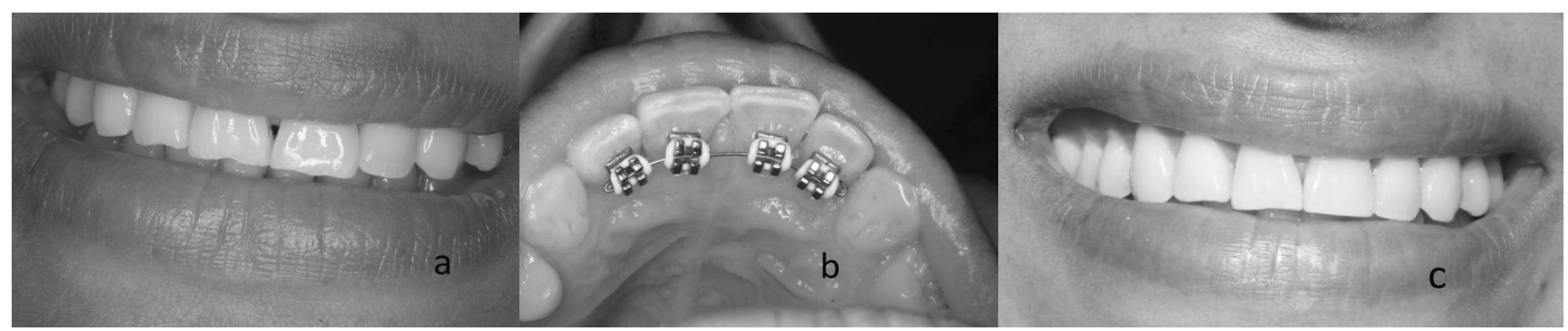

Figure 5. Case five a. Initial, b. During treatment, c. After treatment

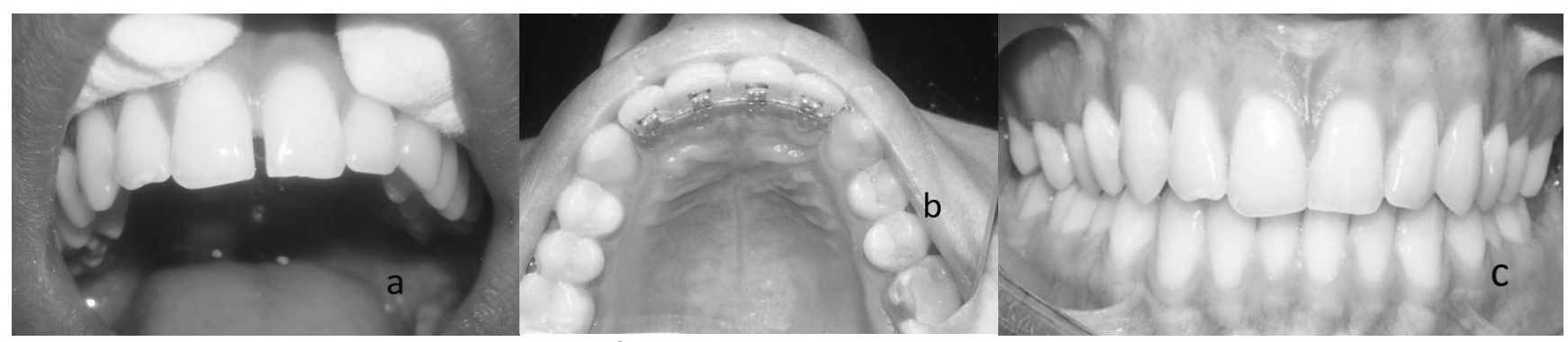

Figure 6. Case six a. Initial, b. During treatment, c. After treatment

period of two years. On examination of oral cavity about $3 \mathrm{~mm}$ diatema was seen. Lingual orthodontic therapy was offered to her. The case was finished in two months and patient is on fixed retention now.

\section{Case four}

This case was a 28 years old female, Nurse by profession. Her chief concern was the increasing gap between her upper front teeth. Due to her profession, she was desperate to treat her problem by any means. Because of the size of the crown, diastema closure by means of orthodontic treatment was decided. The diastema was closed on 0.016 stainless steel round wire with e-chain application. Treatment time was four months. She is on retention now for one year without any problem.

\section{Case five}

This patient was 27 years old female, dental surgeon by profession. She was worried for the increasing size of the black triangle in between upper front teeth. She was reluctant to smile widely because of the black triangle and used to mask the dark hole by keeping saliva in between teeth. Patient did not agree for the labial orthodontic appliance as well as any gingival surgeries. So the treatment plan of lingual appliance therapy and proximal stripping of the enamel followed by space closure was adopted for her. It took three months to treat her problem. At the end of the treatment minor reshaping of the incisal edge was done to give better smile line. Patient is kept on fixed retention.

\section{Case six}

This patient is 22 years old boy presented with the chief complain of gap between front teeth. On examination 2.5 $\mathrm{mm}$ midline distema was seen secondary to thick frenal attachment. Lingual orthodontic therapy to close the distema was planned. Space was closed on 0.016 " stainless steel wire with power chain application. Total treatment time was four months which was followed by frenectomy. Patient is given figure of eight tie with $0.25 \mathrm{~mm}$ stainless steel wire for holding the treatment outcome till the fixed retainer is given.

\section{DISCUSSION}

It is not uncommon that we encounter cases with midline diastema and black triangle quite often in our practice. For the general dental practioners it is always dilemma whether to veneer the case or to close the gap by orthodontic teeth movement. The treatment of the midline diastema should always be governed by different factors. One of them is the size and shape of the incisors. If the size and shape of of the incisors are normal, then it is wise to go for orthodontic treatment. However if the teeth are microdontic, veneering or laminates will be better aesthetically. In case of the anterior black triangle, the gingival papilla is receded bellow the embrasure line and contact point of the incisors is situated incisally. 
The rationale of treatment of anterior black triangle with proximal stripping and orthodontic teeth movement is to move the contact point more apically. ${ }^{1}$ In the cases presented above we have applied simple mechanics to close the space between upper anterior to enhance the appearance. The same standard of results is achievable with labial orthodontic treatment, but the labial treatment options may not be always acceptable to all the patients because of the visible nature of the appliance. Mostly adult patients opt for invisible way of treatment. We have modified the labial technique into lingual side. The brackets are bonded in such as way that there is no gross angulation of the bracket slots so that stainless steel wire can be applied readily on the first visit or on the second visit.

\section{CONCLUSION}

Lingual appliance therapy can be applied in our daily practice by slight modification of labial appliance to correct simple problems in purely invisible way.

12. Gkantidis N, Kolokitha OE, Topouzelis N. Management of maxillary midline diastema with emphasis on etiology. J Clin Pediatr Dent 2008;32(4):265-72.

13. Gribble AR. Multiple diastema management: an interdisciplinary approach. J Esthet Dent 1994;6(3):97-102.

14. 14. Haynes S. Treatment of a large maxillary median diastema associated with four supernumerary teeth. Dent Pract Dent Rec 1972 Mar;22(7):275-8.

15. Massey WR. Closure of maxillary midline diastema with frenectomy and corticotomy. J Ga Dent Assoc 1972;46(2):26-7.

16. Schmuth GP. [Indications for surgical-orthodontic treatments in upper median diastema]. Fortschr Kieferorthop 1970 Jul;30(4):5236.

17. Wright $G$, Shinn D. Treatment of a median diastema with permanent retention. Dent Pract Dent Rec 1971 Nov;22(3):81-4.

18. Shalish M, Cooper-Kazaz R, Ivgi I, Canetti L, Tsur B, Bachar E, et al. Adult patients' adjustability to orthodontic appliances. Part I: a comparison between Labial, Lingual, and InvisalignTM. Eur J Orthod Jul 12.

19. Muir JC. Lingual orthodontic appliances: invisible braces. $N Z$ Dent J $1991 \mathrm{Apr} ; 87(388): 57-9$

10. Cao HJ, Liu K, Qiao L. [Clinical analysis and treatment of 68 spaced dentition cases]. Shanghai Kou Qiang Yi Xue 1994 Jun;3(2):68-70.

11. Chu FC, Siu AS, Newsome PR, Wei SH. Management of median diastema. Gen Dent 2001 May-Jun;49(3):282-7; quiz 8-9. 